Erratum

\title{
PATTERNS OF PRESCRIPTION AND ADR MONITORING OF DRUGS IN THE MANAGEMENT OF NEUROPATHIC PAIN IN A TERTIARY CARE TEACHING HOSPITAL
}

\author{
SUBHRANSU SEKHAR JENA ${ }^{1}$, MONALISA JENA ${ }^{2}$, NIBEDITA PATRO ${ }^{3}$, SWATI MISHRA ${ }^{2}$, MAITREYEE PANDA ${ }^{3}$, \\ MRUTUNJAY DASH ${ }^{4}$
}

1Department of Neurology, IMS and SUM Hospital, SOA University, Bhubaneswar, Odisha, ${ }^{2}$ Department of Pharmacology, IMS and SUM Hospital, SOA University, Bhubaneswar, Odisha, ${ }^{3}$ Department of Dermatology, IMS and SUM Hospital, SOA University, Bhubaneswar, Odisha, ${ }^{4}$ Department of Paediatrics, IMS and SUM Hospital, SOA University, Bhubaneswar, Odisha

Email: drmonalisajena@gmail.com

https://innovareacademics.in/journals/index.php/ijpps/article/view/2706

\section{ABSTRACT}

Objective: Neuropathic pain arises from damage or pathological changes in the peripheral or central nervous system. The pain is difficult to treat as standard treatment with conventional analgesics doesn`t typically provide effective relief of pain.

Methods: It was a one-year study of utilization and analysis of prescriptions for PNDs (Painful neuropathic disorders). The parameters evaluated were demographic profile of the patient (age and gender), type and etiology of PNDs, drug data (name of the group of drugs with individual drugs, mono or polytherapy, number of drugs per prescription, formulation) and associated adverse drug reactions (ADR) with the prescribed drug.

Results: Maximum number of patients of PNDs resides in the age group of 18 - 35 yrs (41.2\%) \& more common in females. The most common PND encountered was painful diabetic neuropathy (43.9\%) followed by cervical and lumbar radiculopathy, postherpetic neuralgia. 2942 drugs were prescribed in 1020 prescriptions out of which $96.8 \%$ were oral and $3.2 \%$ were topical formulations. Most frequently prescribed group of the drug was tricyclic antidepressants (27.3\%) followed by anticonvulsants (25.3\%). Polypharmacy was seen $89.7 \%$ as compared to monotherapy (10.3\%). Only 132 ADRs of various types were seen. The most common organ system affected was the central nervous system followed by gastro intestinal systems. The most common drugs implicated for ADRs were TCAs (24.4\%), anticonvulsants (16.6\%), and Pregabeline (9.8\%). There were no fatal adverse events. Mild to moderate ADRs included constipation, nausea, vomiting, drowsiness, dryness of mouth.

Conclusions: The choice of drug depends on etiology of neuropathic pain, drug efficacy and availability and also on ADR profile.

Keywords: PNDs, Polypharmacy, TCAs, Anticonvulsants, Pregabaline, ADRs

Respected sir,

I have published an original article in the International Journal of Pharmacy and Pharmaceutical Sciences in 2014. I have published it as an affiliation of

Department of Neurology, IMS and SUM Hospital, SOA University, Bhubaneswar, Odisha. For the MCI purpose, it needs to be changed and should read as Assistant Professor in the Department of Medicine, IMS and SUM Hospital, SOA University, Bhubaneswar, Odisha. 